\title{
Properties of poly(lactic acid) nanocomposites based on montmorillonite, sepiolite and zirconium phosphonate
}

\author{
K. Fukushima $^{1 *}$, A. Fina ${ }^{1}$, F. Geobaldo ${ }^{2}$, A. Venturello ${ }^{2}$, G. Camino $^{1}$ \\ ${ }^{1}$ Department of Applied Science and Technology, Polytechnic of Turin, V.le Teresa Michel 5, 15121 Alessandria, Italy \\ ${ }^{2}$ Department of Applied Science and Technology, Polytechnic of Turin, Corso Duca degli Abruzzi 24, 10129 Torino, Italy
}

Received 18 April 2012; accepted in revised form 22 June 2012

\begin{abstract}
Poly(lactic acid) (PLA) based nanocomposites based on $5 \mathrm{wt} \%$ of an organically modified montmorillonite (CLO), unmodified sepiolite (SEP) and organically modified zirconium phosphonate (ZrP) were obtained by melt blending. Wide angle X-ray scattering (WAXS) and scanning electron microscopy (SEM) analysis showed a different dispersion level depending on the type and functionalisation of nanoparticles. Differenctial scanning calorimetric (DSC) analysis showed that PLA was able to crystallize on heating, and that the addition of ZrP could promote extent of PLA crystallization, whereas the presence of CLO and SEP did not significantly affect the crystallization on heating and melting behaviour of PLA matrix. Dynamic Mechanical Thermoanalysis (DMTA) results showed that addition of all nanoparticles brought considerable improvements in $E^{\prime}$ of PLA, resulting in a remarkable increase of elastic properties for PLA nanocomposites. The melt viscosity and dynamic shear moduli $\left(G^{\prime}, G^{\prime \prime}\right)$ of PLA nanocomposites were also enhanced significantly by the presence of CLO and SEP, and attributed to the formation of a PLA/nanoparticle interconnected structure within the polymer matrix. The oxygen permeability of PLA did not significantly vary upon addition of SEP and ZrP nanoparticles. Only addition of CLO led to about $30 \%$ decrease compared to PLA permeability, due to the good clay dispersion and clay platelet-like morphology. The characteristic high transparency of PLA in the visible region was kept upon addition of the nanoparticles. Based on these achievements, a high potential of these PLA nanocomposites in sustainable packaging applications could be envisaged.
\end{abstract}

Keywords: nanocomposites, PLA, montmorillonite clay, sepiolite, zirconium phosphonate

\section{Introduction}

During the past decade, the issue of sustainability has been high on the European Union (EU) agenda, encouraging academia and industry to develop sustainable alternatives thus aiming to preserve resources for future generations. The successful promotion and use of biological, renewable materials for the production of packaging materials will satisfy a number of the EU objectives [1]. To date, packaging materials have been, to a large extent, based on non-renewable materials. The only widely used renewable packaging materials are paper and board which are based on cellulose, the most abundant renewable polymer world-wide. However, major efforts are under way to identify alternative nonfood uses of agricultural crops and the production of packaging materials, based on polymer from agricultural sources, could become a major use of such crops [2-4].

Indeed such alternative bio-based packaging materials have attracted considerable research and development interest for long time [1,4] and in recent years the materials are reaching the market. Among all bio-based biodegradable polymers studied, poly (lactic acid) (PLA) appears to be one of the most attractive polymers commercially available, because

\footnotetext{
${ }^{*}$ Corresponding author, e-mail: kikku.fukushima@gmail.com
} (c) BME-PT 
of its biodegradability, ease of processing, transparency and price. In general, commercial PLA grades are copolymers of poly (L-lactic acid) and poly(D,L-lactic acid), which are produced from Llactides and D,L-lactides respectively. The ratio of L-enantiomers to D, L-enantiomers is known to affect the properties of PLA [5, 6], i.e. whether the materials are semicrystalline or amorphous. There is increasing interest in using PLA for disposable degradable plastic articles; however, there are properties such as flexural properties, gas barrier properties, high melt viscosity and melt strengh/'elasticity' during processing, that are often not good enough for some end-use applications, such as blow molding $[7,8]$. To improve the physical properties of PLA, especially in terms of thermomechanical stability, addition of different fillers (nanoparticles) in PLA was explored [2, 9-11]. Most of the literature regarding nanocomposites is devoted to lamellar layered silicates, in particular organically modified montmorillonites due to their ability to significantly enhance several polymer physical properties as compared to unmodified layered silicate clays, including gas barrier, flame retardancy, thermal stability and influence on the polymer biodegradation rate [2, 12-14]; however, needle like phyllosilicates (sepiolites) and zirconium phosphate are also reported in literature [15-21].

Sepiolite is a layered hydrated magnesium silicate characterized by a needle like morphology based on alternated blocks of tunnels in the fibre direction [16] and very high surface area (BET $374 \pm 7 \mathrm{~m}^{2} / \mathrm{g}$ ) [23] as compared to layered phyllosilicates (BET $82 \pm 1 \mathrm{~m}^{2} / \mathrm{g}$ ) [23, 24]. The addition of sepiolite has been reported to lead an improvement of the mechanical properties in various polymers, such as poly (vinylidene fluoride) and poly(methyl methacrylate) $[25,26]$, poly(styrene butadiene) block copolymers [27], ethylene-propylene (EPM) compounds [28] and natural rubber [29]. Based on the few papers on PLA, Poly ( $\varepsilon$-caprolactone) (PCL), PP and Poly (butylene terephthalate) (PBT) $[15,16]$, the possibility of an unmodified sepiolite to well disperse in polymers by melt blending was evidenced and mainly attributed to the large concentration of surface silanols, spaced every $0,5 \mathrm{~nm}$ along the length of sepiolite needle [30-32], that are easily available for coupling reactions with local polarity on polymer chains.
Zirconium bis(monohydrogen orthophosphate) monohydrate, $\left(\alpha-\mathrm{Zr}\left(\mathrm{HPO}_{4}\right)_{2}\left(\mathrm{H}_{2} \mathrm{O}\right)(\alpha-\mathrm{ZrP})\right)$, has a layered structure with many interesting properties, such as high density of grafted organic modifiers, high thermal stability [33], possible achievement of large aspect ratios, high elastic modulus and the potential to delaminate and become intercalated within the polymer $[17,18]$. PLA/zirconium phosphate composites has been studied and showed intumescent flame-retardant properties [34]. However, to the best of our knowledge, no studies on layered zirconium phosphonate PLA nanocomposites have been reported for possible packaging applications.

The aim of this work is to improve melt viscosity, thermo-mechanical and gas barrier properties of PLA by mixing it with organically modified montmorillonite, unmodified sepiolite and modified zirconium phosphonate, and thus producing final PLA nanocomposites with properties able to enlarge the PLA application fields.

\section{Experimental section}

\subsection{Materials}

The poly(lactic acid) - PLA, 2002D -, average molecular weight $121400 \mathrm{~g} / \mathrm{mol}$, ratio $96 \%$ L-lactide to $4 \%$ D-lactide units, MFR $6.4 \mathrm{~g} / 10 \mathrm{~min}$, was a commercial grade supplied by NatureWorks, Minneapolis Minnesota, USA. One commercial montmorillonite modified with a ditallow, dimethyl ammonium salt - CLOISITE 20A - was supplied by Southern Clay, Cheshire, UK, commercial unmodified sepiolite - PANGEL S9 - supplied by Tolsa, S.A, Madrid, Spain and $\alpha$-carboxyl-ethane zirconium phosphonate - ZrP 102 - (ultrapure $>99 \%$ ) were supplied by Prolabin \& Tefarm, Perugia, Italy. The characteristics of the nanoparticles used in this work are listed in Table 1.

Prior to the melt blending, polymer matrix was dried at $70^{\circ} \mathrm{C}$ under vacuum for $4 \mathrm{~h}$ to achieve a residual moisture less than $190 \mathrm{ppm}$. Nanoparticles were dried at $100^{\circ} \mathrm{C}$ under vacuum for $10 \mathrm{~h}$ for CLO and SEP; and $4 \mathrm{~h}$ for $\mathrm{ZrP}$ to achieve residual moisture less than $250 \mathrm{ppm}$. Nanocomposites were prepared at 5\% filler loading by melt blending using a Microextruder DSM Micro $15 \mathrm{ml}$ Twin Screw Compounder, with a mixing time of $5 \mathrm{~min}$, at $180^{\circ} \mathrm{C}$ in nitrogen flow. The mixing was performed at two different rotor speeds: $60 \mathrm{rpm}$ in the loading step and 
Table 1. Characteristics of nanoparticles

\begin{tabular}{|c|c|c|c|c|}
\hline Nanoparticle type & Commercial name & Modifier structure & Functional formula of nanoparticle & Notation in text \\
\hline Montmorillonite ${ }^{a), b)}$ & CLOISITE 20A & $\begin{array}{l}\mathrm{H}_{3} \mathrm{C} \\
\mathrm{H}_{3} \mathrm{C}^{-} \mathrm{N}^{+}-\mathrm{HT}_{\mathrm{HT}}^{-\mathrm{HT}^{-}}\end{array}$ & $\begin{array}{l}\mathrm{M}_{\mathrm{x}}\left(\mathrm{Al}_{4-\mathrm{x}} \mathrm{Mg}_{\mathrm{x}}\right) \mathrm{Si}_{8} \mathrm{O}_{20}(\mathrm{OH})_{4} \\
\mathrm{M} \text { : monovalent cation; } \mathrm{x} \text { : degree of isomor- } \\
\text { phous substitution (between } 0.5 \text { and } 1.3 \text { ) }\end{array}$ & CLO \\
\hline Sepiolite ${ }^{c)}$ & PANGEL S9 & None & $\mathrm{Si}_{12} \mathrm{O}_{30} \mathrm{Mg}_{8}(\mathrm{OH})_{4} \cdot\left(\mathrm{H}_{2} \mathrm{O}\right)_{4} \cdot 8 \mathrm{H}_{2} \mathrm{O}$ & SEP \\
\hline $\begin{array}{l}\alpha \text {-carboxyl-ethane } \\
\text { Zirconium phosphonate }^{\mathrm{d})}\end{array}$ & ZrP 102 & $\mathrm{CH}_{2} \mathrm{CH}_{2} \mathrm{COOH}$ & $\mathrm{Zr}\left(\mathrm{O}_{3} \mathrm{P}\left(\mathrm{CH}_{2}\right)_{2} \mathrm{COOH}\right)_{2}$ & $\mathrm{ZrP}$ \\
\hline
\end{tabular}

HT: hydrogenated linear alkyl chains: $\mathrm{C}_{8-18}$

a) Organic modifier content $c a .38 \mathrm{wt} \%$ according to CLOISITE 20A technical data sheet.

b) Functional formula taken from reference [2].

${ }^{c)}$ Functional formula taken from reference [22].

d) Functional formula taken from reference [35].

$100 \mathrm{rpm}$ during mixing. Sheets were obtained by compression molding in a hot-plate hydraulic press at $190^{\circ} \mathrm{C}$ and allowed to cool $\left(\mathrm{ca} .-10^{\circ} \mathrm{C} / \mathrm{min}\right)$ to room temperature under pressure $\left(60 \mathrm{Kgf} / \mathrm{cm}^{2}\right)$. Morphological and thermo-mechanical characterizations were made on compression moulded $0.6 \mathrm{~mm}$ films, melt rheological measurements were carried out on compression moulded $1 \mathrm{~mm}$ films, optical transparency analyses were made on compression moulded $40-50 \mu \mathrm{m}$ films and oxygen gas barrier analyses were performed on compression moulded $320 \mu \mathrm{m}$ films (for PLA/ZrP) and on chill roll extruded 150-160 $\mu \mathrm{m}$ films (for PLA, PLA/CLO and PLA/SEP). These last films were moulded at $180^{\circ} \mathrm{C}$, passing the specimens by a chill roll with $150 \mu \mathrm{m}$ opening of several slits and allowed to cool to room temperature. In the case of PLA and PLA/CLO chill roll films, previous to the film cooling process to room temperature, these were biaxially stretched above PLA glass transition temperature (above $60^{\circ} \mathrm{C}$ ) to obtain films with $50-70 \mu \mathrm{m}$ thick.

\subsection{Characterization techniques}

Wide Angle X-Ray Spectra (WAXS) were recorded using a Thermo ARL diffractometer X-tra 48, at room temperature in the range $1-30^{\circ}(2 \theta)$ (step size $=0.02^{\circ}$, scanning rate $=2 \mathrm{~s} / \mathrm{step}$ ) by using filtered $\mathrm{CuK} \alpha$ radiation $(\lambda=1.54 \AA)$.

Scanning electron microscopy (SEM) was carried out on surfaces obtained after sectioning with a microtome diamond knife to avoid large surface roughness sputtered with gold, using a LEO $1400 \mathrm{VP}$ Series (Carl Zeiss, Oberkochen, Germany) equipped with energy dispersive spectroscopy (EDS).

Transmission electron microscopy (TEM) analyses were performed with a high-resolution equipment.
Ultrathin sections of about $100 \mathrm{~nm}$ thick were cut at room temperature with a microtome equipped with a diamond knife and placed on a 200-mesh copper grid. Differential Scanning Calorimetry (DSC) tests were carried on a DSC Q100 TA Instruments (New Castle, DE, USA) under nitrogen atmosphere at a scanning rate of $10^{\circ} \mathrm{C} / \mathrm{min}$, sample size $3-5 \mathrm{mg}$ in aluminium pans. Thermal history of samples was erased by a preliminary heating cycle at $10^{\circ} \mathrm{C} / \mathrm{min}$ from $-20^{\circ} \mathrm{C}$ to $+280^{\circ} \mathrm{C}$. The glass transition temperature $\left(T_{\mathrm{g}}\right)$, cold crystallization temperature $\left(T_{\mathrm{cc}}\right)$, melting temperature $\left(T_{\mathrm{m}}\right)$, cold crystallization enthalpy $\left(\Delta H_{\mathrm{cc}}\right)$ and melting enthalpy $(\Delta H \mathrm{~m})$ were determined from second heating scan at $10^{\circ} \mathrm{C} / \mathrm{min}$. Dynamic-Mechanical Thermal Analysis (DMTA) was performed on compression moulded $6 \times 20 \times$ $0.6 \mathrm{~mm}^{3}$ films, using a DMA Q800 TA Intruments (New Castle, DE, USA) in tension film clamp. The temperature range analysed was from +20 to $+80^{\circ} \mathrm{C}$, at a heating rate of $2^{\circ} \mathrm{C} / \mathrm{min}, 1 \mathrm{~Hz}$ frequency, in strain controlled mode, 15 micron of amplitude and static loading $=125 \%$ dynamic loading. At least two samples of each material were tested and the average value of these parameters for each material was calculated and reported. The estimated experimental error based on the Storage Modulus and Tan Delta deviations between repeated tests was $c a$. $10 \%$.

Melt rheological measurements were performed on ARES instrument (New Castle, DE, USA) with a torque transducer capable of measurements over the range of 0.02 to $200 \mathrm{~g} \cdot \mathrm{cm}$. Dynamic oscillatory shear measurements were performed by applying a time dependent strain of $\gamma(t)=\gamma_{0} \sin (\omega t)$ and the resultant shear stress is $\sigma(t)=\gamma_{0}\left[G^{\prime} \cdot \sin (\omega t)+\right.$ $G^{\prime \prime} \cdot \cos (\omega t)$ ], with $G^{\prime}$ and $G^{\prime \prime}$ being the storage and loss modulus, respectively. Measurements were con- 
ducted by using a set of $25 \mathrm{~mm}$ diameter parallel plates with a sample thickness of $1 \mathrm{~mm}$. The strain amplitude was fixed to $1 \%$ for PLA/CLO and 10\% for neat PLA and PLA/SEP systems, in order to obtain reasonable signal intensities even at low frequency $(\omega)$ to avoid the non linear response. For each type of material the limits of linear viscoelasticity were determined by performing strain sweeps at series of fixed $\omega \mathrm{s}$. The dynamic viscoelastic curves were obtained by using the principle of timetemperature superposition and shifted to a common reference temperature of $190^{\circ} \mathrm{C}$ which was chosen as the most representative of a typical processing temperature of PLA.

Oxygen gas barrier properties were measured on compression moulded films of $5 \mathrm{~cm}^{2} \times 320 \mu \mathrm{m}$ for PLA/ZrP, on chill roll moulded films of $50 \mathrm{~cm}^{2} \times$ $150-160 \mu \mathrm{m}$ for PLA/SEP and on chill roll moulded films of $50 \mathrm{~cm}^{2} \times 50-70 \mu \mathrm{m}$ for PLA and PLA/CLO, using a permeabilimeter MOCON OX-TRAN 2/21 (Minneapolis, USA). The experimental conditions were $23^{\circ} \mathrm{C}, 760 \mathrm{~mm} \mathrm{Hg}$ pressure, $0 \%$ relative humidity and with permeant concentration of $100 \%$. Two samples were tested for each type of material and average results of permeability (normalised on the thickness) are presented.

Optical transparency of PLA and PLA/composites was obtained using a UV-vis spectrometer CARY 500 (California, USA) on compression moulded $5 \mathrm{~cm}^{2} \times 40-50 \mu \mathrm{m}$. The analysis was performance in transmittance mode from $380-780 \mathrm{~nm}$ wavelength, UV-vis scan rate of $600 \mathrm{~nm} / \mathrm{min}$ and Double Beam Mode. The cumulative transmission over visible spectra was measured to three samples of each material and the average value of these measure- ments was reported for each material type. The estimated experimental error was $c a .10 \%$.

\section{Results and discussion \\ 3.1. Morphology}

\subsubsection{Wide Angle X-ray analysis (WAXS)}

The WAXS pattern of PLA is characterized by a broad amorphous halo with maximum approximately at $2 \theta=17^{\circ}$ (not shown here). These results indicate that PLA matrix was not able to crystallize during the film cooling process $\left(\mathrm{ca} .10^{\circ} \mathrm{C} / \mathrm{min}\right)$, thus obtaining a completely amorphous structure for the polymer matrix at room temperature.

A similar broad WAXS halo with maximum at $c a$. $2 \theta=17^{\circ}$ was observed for PLA/CLO and PLA/ZrP, indicating an amorphous structure of the polymer matrix in these specimens. This result suggests that the addition of these nanoparticles does not induce polymer crystallization under the conditions of film cooling carried out here.

The most significant features are indeed encountered in the lower angle range, which gives indication of the nanoparticles interlayer distance. Figure $1 \mathrm{a}$ and $1 \mathrm{~b}$ represent the WAXS patterns of composites of PLA with CLO and ZrP, compared with the pristine nanoparticles. CLO is characterized by two diffraction peaks at $2 \theta=3.5$ and $7.2^{\circ}$ respectively (Figure 1a); the diffraction peak at $2 \theta=$ $3.5^{\circ}$ correspond to the crystalline plane (001) [11], whereas the weak peak at $7.2^{\circ}$, corresponding to an interlayer distance of $1.24 \mathrm{~nm}$, is likely to be related to a low content of montmorillonite silicates layers without organic modifier insertion [11].

The PLA/CLO nanocomposite exhibited two diffraction peaks at $2.4^{\circ}$ corresponding to an interlayer
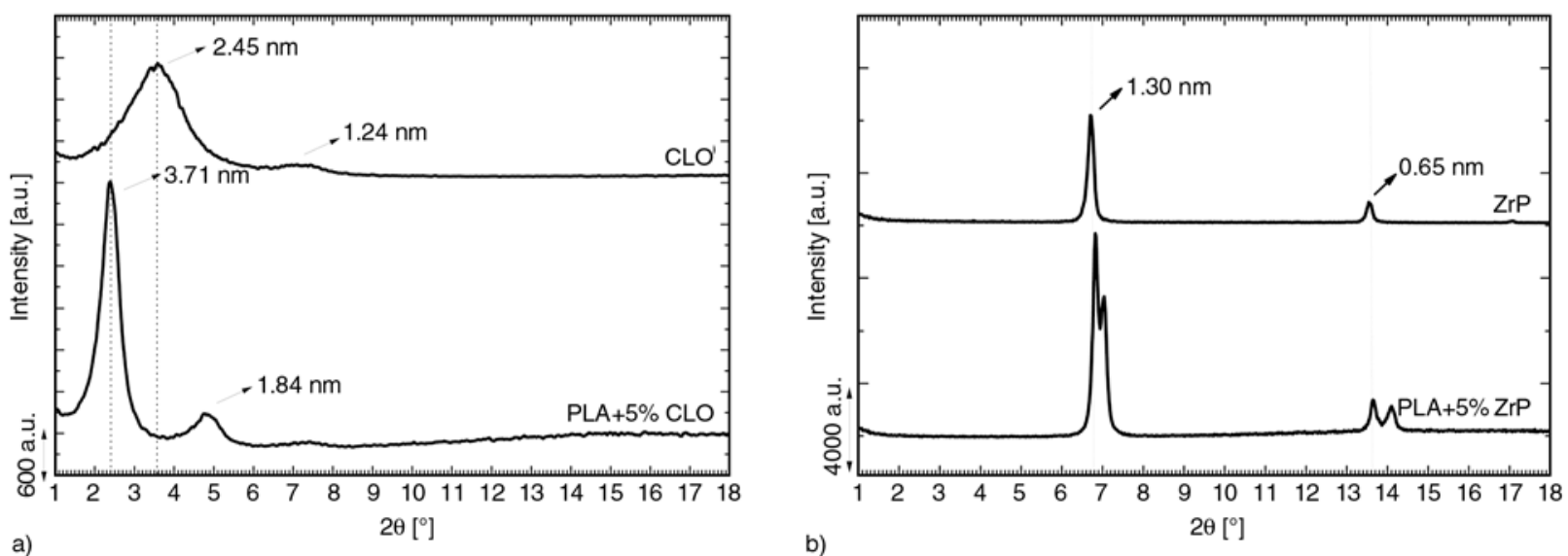

Figure 1. WAXS patterns of PLA based composites with 5\% (a) CLO and (b) ZrP 
spacing of $3.71 \mathrm{~nm}$, and a secondary diffraction peak, $\left(\mathrm{d}_{002}\right)$, at $5.0^{\circ}[8,11]$. An increase in the interlayer spacing from $2.45 \mathrm{~nm}$ in the nanoclay filler to $3.71 \mathrm{~nm}$ in the PLA nanocomposite gave credit to some intercalation occurring during the component blending above the melting temperature of the polymer matrix. This finding showed the possibility of penetration of the PLA chains within the nanoclay galleries on shearing at high temperature.

This intercalation of polymer chains in the CLO silicate layers can be obtained thanks to chemical affinity between the polymer and the clay, originated from the hydrogen bonding between the carbonyl groups of the main chain of PLA molecules and the hydroxyl groups belonging to CLO surface silicate layers $[2,11,15]$. The presence of the organic modifier between CLO layers could also make possible the delamination of CLO silicate layers in PLA/CLO hybrid by high mixing torques during the melt blending process, despite, strong chemical interactions between the organic modifier molecules and PLA matrix would not be expected, considering the non-polar structure of this organic modifier [8].

Figure $1 \mathrm{~b}$ shows the WAXS patterns of the pristine $\mathrm{ZrP}$, showing two characteristic peaks at $2 \theta=6.70$ and $13.5^{\circ}$, which are attributed to the (002) plane for organo-modified $\mathrm{ZrP}$ and pristine $\mathrm{ZrP}$, respectively. Indeed, the main WAXS peak at $6.70^{\circ}(d=$ $1.30 \mathrm{~nm}$ ) indicates greater separation of the $\mathrm{ZrP}$ layers by the presence of the carboxyl-ethane groups $[20,21,35]$, whereas the weaker WAXS peak at $13.5^{\circ}$ corresponds to the interlayer d-spacing of inorganic $\alpha-\mathrm{ZrP}$ as an impurity $[19,35,36]$.

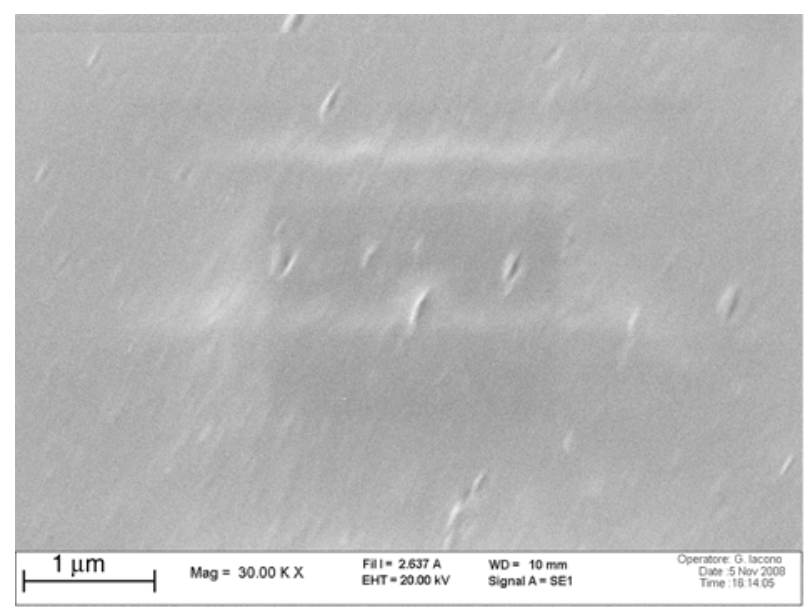

a)
The WAXS patterns of PLA/ZrP hybrid do not show signs of intercalation of PLA into ZrP platelets, likely due to the insufficient interlayer thickness, which is significantly lower in $\mathrm{ZrP}$ as compared to CLO. Indeed, the presence of the sharp peaks at diffraction angles correspondent to $\mathrm{ZrP}$ confirms that, in these compounding conditions, the stacking of parallel zirconium phosphate sheets is not significantly modified.

No information is delivered by WAXS on dispersion of needle-shaped sepiolite in PLA, given the lack of periodic stacking of pristine nanoparticles.

\subsubsection{Scanning electron microscopy (SEM)}

All formulations were observed by SEM on surfaces to study the dispersion and distribution of nanoparticles. SEM micrographs at low magnification (not shown here) reveals no significant presence of agglomerated $(>10 \mu \mathrm{m})$ inorganic nanoparticles regardless the composition. In PLA/CLO a very uniform distribution of small stacks of silicate layers can be observed in the polymer matrix, as shown in Figure 2a. The presence of clay layers is indeed highlighted by the cracks observable on diamond cut surfaces, which are not present in pristine PLA when prepared in the same way. Indeed, such cracks are attributed to delamination between polymer matrix and nanoclay stacks. TEM images (Figure $2 b)$ confirmed the presence of both isolated nanoclay layers and stacks of a few clay layers.

In the case of PLA/SEP, nanofibres emerging from the polymer surface are clearly visible in SEM micrographs (Figure 3). Diameter of these fibres are in the range of 10 to $100 \mathrm{~nm}$, therefore are

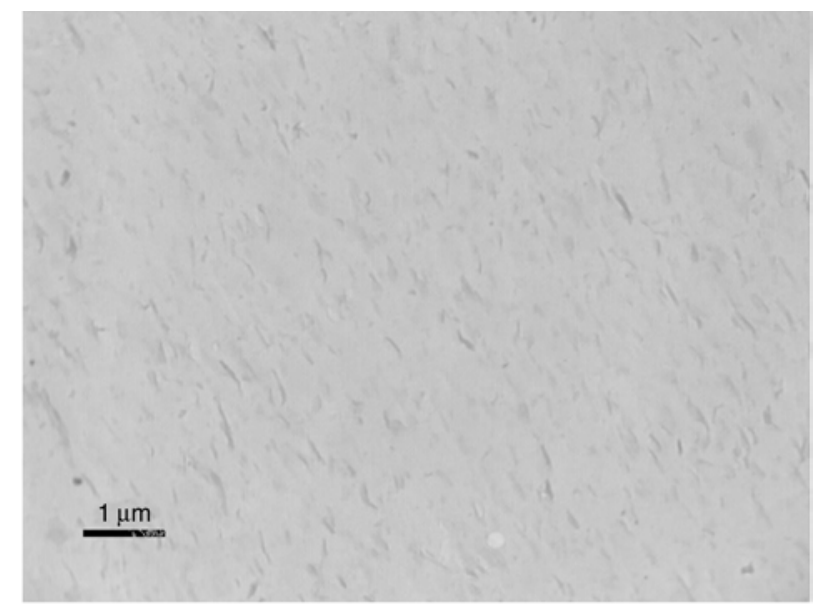

b)

Figure 2. Scanning electron micrograph (a) and transmission electron micrograph (b) for PLA $+5 \%$ CLO 


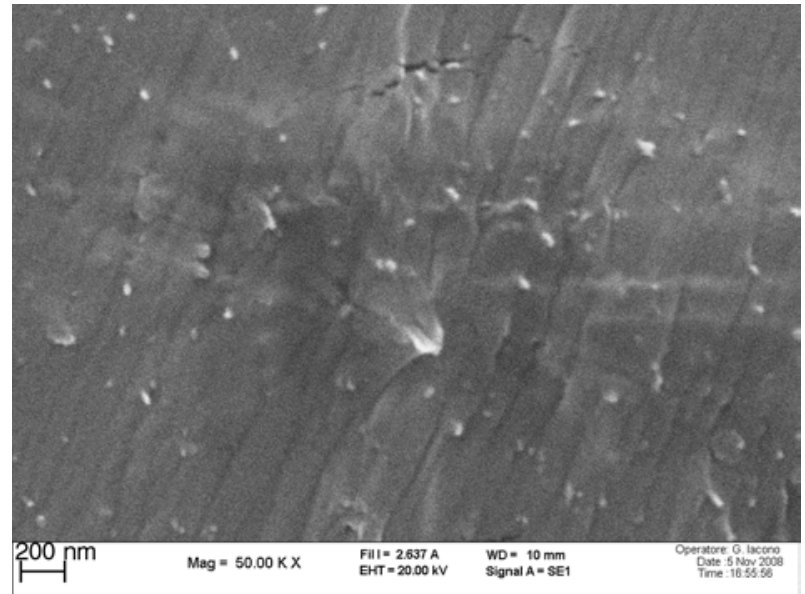

Figure 3. Scanning electron micrographs at $50 \mathrm{kX}$ of magnification for PLA $+5 \%$ SEP. The cracks observed in the polymer matrix corresponds to matrix degradation under electron beam irradiation

assigned to single sepiolite needles and some bundles of a few individual sepiolite needles.

The addition of $5 \% \mathrm{ZrP}$ (Figure 4) reveals the presence of ZrP micro-particles fairly distributed in the polymer surface. However, poor adhesion of the

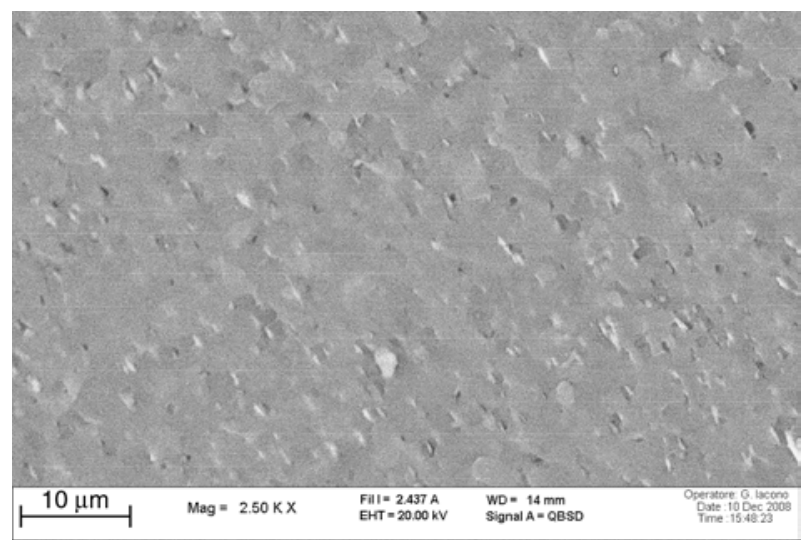

Figure 4. Scanning electron micrographs for PLA $+5 \% \mathrm{ZrP}$

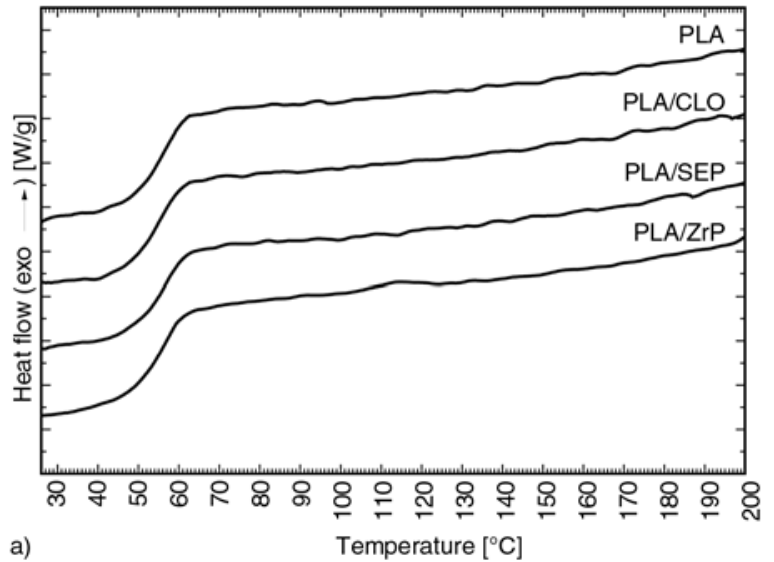

microparticles is evidenced by the presence of holes left by detachment of some $\mathrm{ZrP}$ particles during mirotome cutting. Interestingly enough, SEM micrographs show that $\mathrm{ZrP}$ powder presents a plate-like structure and regular sheets, which can be related to the presence of very sharp WAXS peaks both in pristine $\mathrm{ZrP}$ and in the composite.

\subsection{Thermal analysis (DSC)}

Crystallisation of PLA nanocomposites was studied by means of DSC measurements. In Figure 5, cooling and second heating DSC plots for PLA and composites are reported. On cooling at a rate of $10^{\circ} \mathrm{C} / \mathrm{min}$ (Figure 5a), the pure PLA does not exhibit any exothermic peak, evidencing that no crystallization takes place. Crystallization on cooling of PLA is not significantly affected by the addition of the nanoparticles, as evidenced by the identical DSC thermograms, confirming that all materials addressed here are not able to crystallise at cooling rates of $10^{\circ} \mathrm{C} / \mathrm{min}$ or higher, in agreement with the WAXS analysis which evidenced fully amorphous structures.

Figure $5 b$ reports the DSC thermograms of the second heating curves of PLA and PLA/nanocomposites. PLA partially crystallizes on heating at about $130^{\circ} \mathrm{C}$ (cold crystallization) giving a crystalline phase which melts with a peak endotherm at about $154^{\circ} \mathrm{C}[15,37]$ (see Table 2).

Figure $5 \mathrm{~b}$ and Table 2 show that the addition of CLO and SEP does not significantly affect the crystallization and melting behaviour of PLA, since no significant variations of cold crystallization temperature $\left(T_{\mathrm{cc}}\right)$, enthalpy of cold crystallization $\left(\Delta H_{\mathrm{cc}}\right)$,

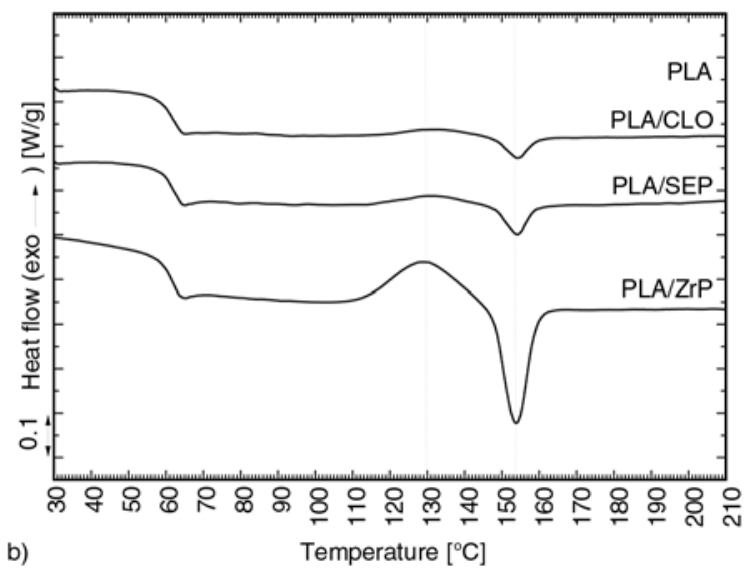

Figure 5. DSC thermograms of PLA and PLA/composites at (a) cooling and (b) second heating. Plots are vertically shifted for the sake of clarity. 
Table 2. DSC data on PLA and PLA/nanocomposites obtained by second heating curves

\begin{tabular}{|l|c|c|c|c|c|}
\hline \multicolumn{1}{|c|}{ Sample } & $\begin{array}{c}\mathbf{T}_{\text {cc }} \text { a) } \\
{\left[{ }^{\mathbf{c}} \mathbf{C}\right]}\end{array}$ & $\begin{array}{c}\Delta \mathbf{H}_{\text {cc }} \\
{[\mathbf{J} / \mathbf{g}]}\end{array}$ & $\begin{array}{c}\mathbf{T}_{\mathbf{m}}{ }^{\text {a) }} \\
{\left[{ }^{\circ} \mathbf{C}\right]}\end{array}$ & $\begin{array}{c}\Delta \mathbf{H}_{\mathbf{m}} \\
{[\mathbf{J} / \mathbf{g}]}\end{array}$ & $\begin{array}{c}\mathbf{T}_{\mathbf{g}} \\
{\left[{ }^{\circ} \mathbf{C}\right]}\end{array}$ \\
\hline PLA & 130 & 2 & 154 & 2 & 61 \\
\hline PLA + CLO & 131 & 2 & 154 & 2 & 61 \\
\hline PLA + SEP & 131 & 3 & 154 & 3 & 61 \\
\hline PLA + ZrP & 129 & 11 & 154 & 12 & 60 \\
\hline
\end{tabular}

a) Temperatures quoted are peak temperatures

melting temperature $\left(T_{\mathrm{m}}\right)$, melting enthalpy $\left(\Delta H_{\mathrm{m}}\right)$ and glass transition temperature $\left(T_{\mathrm{g}}\right)$ were observed. Addition of $\mathrm{ZrP}$ particles neither leads important variations in the $T_{\mathrm{cc}}, T_{\mathrm{m}}$ and $T_{\mathrm{g}}$ of PLA matrix, however, increases of the enthalpy of cold crystallization $(c a .9 \mathrm{~J} / \mathrm{g})$ and of the melting enthalpy of neat PLA ( $c a .10 \mathrm{~J} / \mathrm{g}$ ) could be detected by the presence of these particles (see Figure $5 \mathrm{~b}$ and Table 2). These increases of $\Delta H_{\mathrm{cc}}$ and $\Delta H_{\mathrm{m}}$ obtained by $\mathrm{ZrP}$ based composites indicate that the addition of these particles promotes extent of crystallization of the PLA on heating, which is most likely related to the regular distribution of $\mathrm{ZrP}$ micronic particles (previously verified through WAXS and SEM analysis) able to act as nucleating agents of PLA crystallization.

It is also possible that a higher dispersion level of CLO and SEP particles into the PLA as compared to $\mathrm{ZrP}$, could interfere with polymer molecules crystallization instead of enhancing it. In general, it has been reported the possible nucleating effect of well dispersed organoclay layers on polymer crystallization of PLA [2, 9-11]; however, it has been also reported that high interactions between polymer matrix and nanoscale particles, can provoke that some polymer chains can be attached to the clay layers, and then partially immobilized and hindered from taking part in the flow process and their crystallization process $[8,38]$. Accordingly, in addition to acting as nucleation agents, the silicates particles of CLO and SEP could also become retardant of crystallization, acting as physical hindrance if there are important interactions between polymer matrix and clay, and consequently obtaining insignificant changes in the crystallization and melting process of PLA.

\subsection{Dynamic-mechanical thermal analysis} (DMTA)

The dynamic-mechanical experiments of PLA and nanocomposites are reported in Figure 6, Figure 7

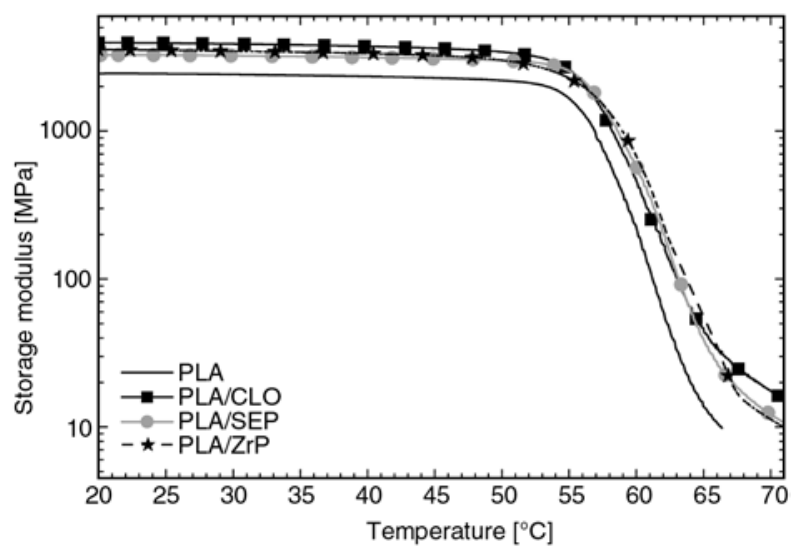

Figure 6. Temperature dependence of storage modulus $\left(E^{\prime}\right)$ for PLA and PLA/composites

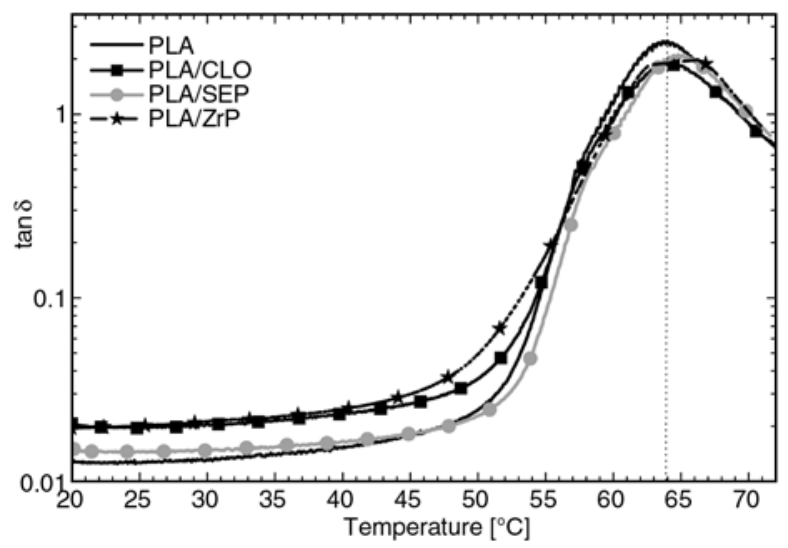

Figure 7. Temperature dependence of $\tan \delta$ for PLA and PLA/composites

and Table 3, showing the temperature dependence of Storage Modulus $\left(E^{\prime}\right)$ and $\tan \delta$ for all the studied materials. A general enhancement of $E^{\prime}$ below $T_{\mathrm{g}}$ was observed compared to neat PLA: at $20^{\circ} \mathrm{C}, E^{\prime}$ increases of ca. 60,35 and $45 \%$ were obtained for PLA/CLO, PLA/SEP and PLA/ZrP, respectively (Table 3). Higher enhancements of $E^{\prime}$ were observed above $T_{\mathrm{g}}$ : at $65^{\circ} \mathrm{C}$ increases of $c a .150,120$ and $170 \%$ were obtained for PLA/CLO, PLA/SEP and PLA/ZrP, respectively.

The dynamo-mechanical results show improvements in $E^{\prime}$ with the addition of all nanoparticles, indicating that addition of particles into PLA matrix results in a remarkable increase of elastic properties for PLA composites, more noticeable at higher temperatures (above $60^{\circ} \mathrm{C}$ ), which means an increase of thermal-mechanical stability for the composites at high temperatures [38]. The increase of $E^{\prime}$ for composites with temperature compared to that of neat PLA may be attributed to a restriction in the movements of the polymer chains above $T_{\mathrm{g}}[2,38]$. How- 
Table 3. $E^{\prime}$ and $\tan \delta$ values of PLA and PLA/composites at 20 and $65^{\circ} \mathrm{C}$. Estimated experimental error $\pm 10 \%$

\begin{tabular}{|l|c|c|c|}
\hline \multicolumn{1}{|c|}{ Sample } & $\begin{array}{c}\mathbf{E}^{\prime} \text { at } \mathbf{~ 2 0}^{\circ} \mathbf{C} \\
{[\mathbf{M P a}]}\end{array}$ & $\begin{array}{c}\mathbf{E}^{\prime} \text { at } \mathbf{6 5}^{\circ} \mathbf{C} \\
{[\mathbf{M P a}]}\end{array}$ & $\begin{array}{c}\mathbf{T} \text { at } \mathbf{t a n} \boldsymbol{\delta}_{\text {max }} \\
{\left[{ }^{\circ} \mathbf{C}\right]}\end{array}$ \\
\hline PLA & 2429 & 13 & 64 \\
\hline PLA + CLO & 3815 & 32 & 65 \\
\hline PLA + SEP & 3264 & 28 & 64 \\
\hline PLA + ZrP & 3529 & 35 & 65 \\
\hline
\end{tabular}

ever, given the very low storage modulus values of neat PLA above $T_{\mathrm{g}}$, these enhancement in modulus above this temperature have limited practical interest, absolute values for $E^{\prime}$ being below $50 \mathrm{MPa}$ for all composites.

This improved strength has also been observed for other polymer/clay nanocomposites, depending on the degree of dispersion of clay in the polymer matrix $[13,15]$. In the case of PLA nanocomposites in this study, all composites present $E^{\prime}$ improvements both below and above glass transition temperature, explained by strong interactions between the particles and PLA molecules originated from hydrogen bonding between the carbonyl groups of PLA and the hydroxyl groups belong to the structure of CLO, SEP and ZrP (see Table 1). Indeed, such interactions have been previously verified by other researchers in biopolymer nanocomposites based on similar nanoparticles rich of surface silanol groups ( $\mathrm{Si}-\mathrm{OH})[21,39,40]$. In this case, they have corroborated the possible spontaneous assembly of the biopolymer matrix and nanoparticles through hydrogen-bonding interactions, by the observed infrared perturbation of the $\mathrm{O}-\mathrm{H}$ stretching vibrations assigned to the surface silanol groups. Interestingly enough, similar increases of $E^{\prime}$ were obtained upon the addition of $\mathrm{ZrP}$ into PLA as compared to CLO and SEP (even higher at $65^{\circ} \mathrm{C}$ ), despite its low dispersion level into the PLA matrix according to WAXS and SEM analysis, and probably attributed to the high crystallinity of $\mathrm{ZrP}$ particles as well as to the very regular distribution of $\mathrm{ZrP}$ micronic particles along all the polymer matrix (see Figure $1 b$ and 4).

The presence of the particles does not show significant shift of $\tan \delta$ (Figure 7 and Table 3) for all composites compared to pure PLA, in agreement with DSC analysis.

\subsection{Melt rheology}

The rheological properties of polymer nanocomposites are directly related to their melt behavior during processing, such as extrusion or injection moulding. Moreover, rheology offers a mean to assess the level of filler dispersion in nanocomposites directly in the molten state, given that rheological properties of particle-filled materials are sensitive to the structure, particle size, shape and interface characteristics of the dispersed phase [2].

The rheological behavior was studied for the PLA nanocomposites containing well dispersed particles (CLO and SEP); the linear dynamic viscoelastic curves for these materials as well as neat PLA are shown in Figure 8. Both $G^{\prime}(\omega)$ and $G^{\prime \prime}(\omega)$ moduli of nanocomposites increase at all frequencies as compared to PLA. At high frequencies, the values of $G^{\prime}(\omega)$ and $G^{\prime \prime}(\omega)$ of neat PLA are practically unaffected by the presence of nanoparticles. However, at low frequency, the presence of nanoparticles CLO and SEP induces an increase of $G^{\prime}(\omega)$ and $G^{\prime \prime}(\omega)$ compared to neat PLA (see Figure 8a, b). Indeed, at $\omega<10 \mathrm{rad} \cdot \mathrm{s}^{-1}$ for PLA/CLO and $\omega<$ $0.05 \mathrm{rad} \cdot \mathrm{s}^{-1}$ for PLA/SEP, both $G^{\prime}(\omega)$ and $G^{\prime \prime}(\omega)$ display a significantly diminished frequency dependence as compared to PLA. The lower frequency dependence and the higher absolute values of the dynamic moduli observed for PLA/CLO compared to PLA suggest the formation of a 'network' structure in the molten state [41]. This is explained by the presence of highly dispersed silicate layers of CLO which are incapable rotating freely and hence, by imposing small $\omega$, the relaxations of the structure are almost completely prevented. This type of prevented relaxation due to the highly geometric constrains of dispersed silicate layers leads to the marked presence of the pseudo-solid like behavior for PLA/CLO system [41]. Similar results are obtained for PLA/SEP, but only observing the achievement of a spatially linked structure determining $G^{\prime}(\omega)$ plateau for $\omega<0.05 \mathrm{rad} \cdot \mathrm{s}^{-1}$, probably due to its lower dispersion level as compared to PLA/CLO in accordance with SEM results and/or due to the different geometrical features compared to lamellar clay, i.e. needles vs platelets.

The complex viscosity $\left[\left|\eta^{*}\right|(\omega)\right]$ curves are also shown in Figure 8c; it is possible to observe at low 
$\omega$ region $\left(\omega<10 \mathrm{rad} \cdot \mathrm{s}^{-1}\right)$ that the neat PLA shows Newtonian behavior while PLA/CLO $\left(\omega<10 \mathrm{rad} \cdot \mathrm{s}^{-1}\right)$ and PLA/SEP $\left(\omega<0.05 \mathrm{rad} \cdot \mathrm{s}^{-1}\right)$ exhibit a considerable increase of the viscosity with decreasing $\omega$, especially in the case of PLA/CLO. This last behavior is associated to a solid-like behavior commented above, especially for CLO. By increasing the shear rates, shear thinning behavior was observed for CLO and SEP materials, indicating that these nanoparticles do not significantly influence viscosity at
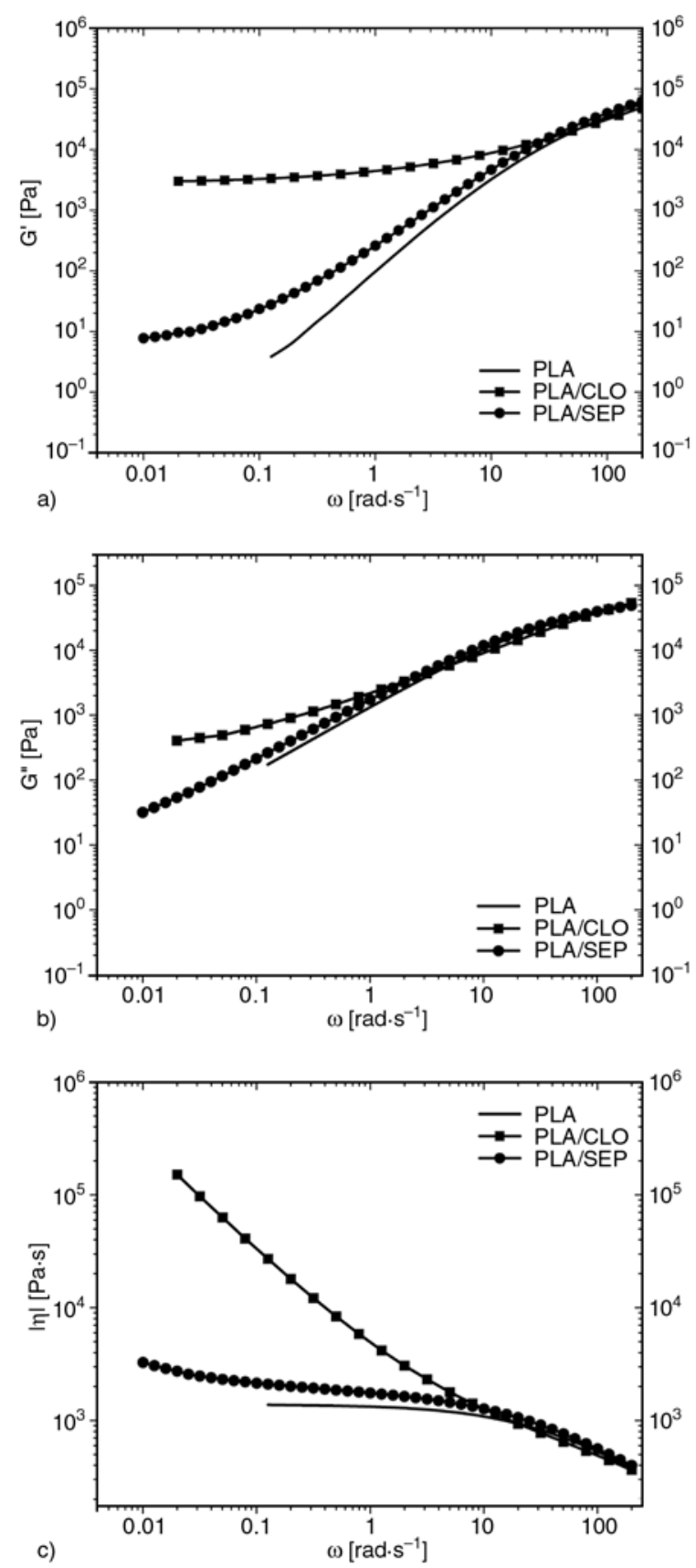

Figure 8. Reduced frequency dependence of (a) storage modulus $\left[G^{\prime}(\omega)\right],(\mathrm{b})$ loss modulus $\left[G^{\prime \prime}(\omega)\right]$, and (c) complex viscosity $\left[\left|\eta^{*}\right|(\omega)\right]$ at $190^{\circ} \mathrm{C}$ of neat PLA and PLA/composites higher frequencies, reaching $\left[\left|\eta^{*}\right|(\omega)\right]$ values analogous to those found for neat polymer.

\subsection{Oxygen barrier properties}

The $\mathrm{O}_{2}$ gas permeability values of pure PLA and several composites are presented in Figure 9, showing that oxygen permeability of PLA does not vary significantly, taking into account the experimental error, upon addition of SEP and ZrP particles. Only addition of $5 \mathrm{wt} \%$ CLO leads to a decrease of the PLA oxygen permeability (by $c a .30 \%$ ).

The higher oxygen barrier properties of CLO nanocomposites as compared to PLA can be explained by the concept of the tortuous path, given to its high clay dispersion, according to WAXS and SEM analysis, and its clay platelets like morphology which maximize the permeant path length due to the large length to width ratio [2]. In the case of SEP, the lack of barrier effect is likely related to its needle like morphology, which cannot play a considerable barrier role of oxygen molecules through the bulk material as compared to platelets morphology of CLO. In the case of ZrP based material, the low dispersion level of lamellar nanoparticles into PLA is assumed to cause the lack of significant effects on permeability.

For food packaging applications is widely common the use of Polystyrene (PS), Polypropylene (PP) and Polyethylene terephthalate (PET), given their good mechanical and oxygen barrier properties in this industrial field. The typical oxygen barrier values of these polymers are listed in Table 4; comparing these results with those obtained for neat PLA (see Figure 9), this results to be an alternative to PS and PP, in terms of oxygen barrier properties. The addition of CLO can decrease the oxygen permeation of neat

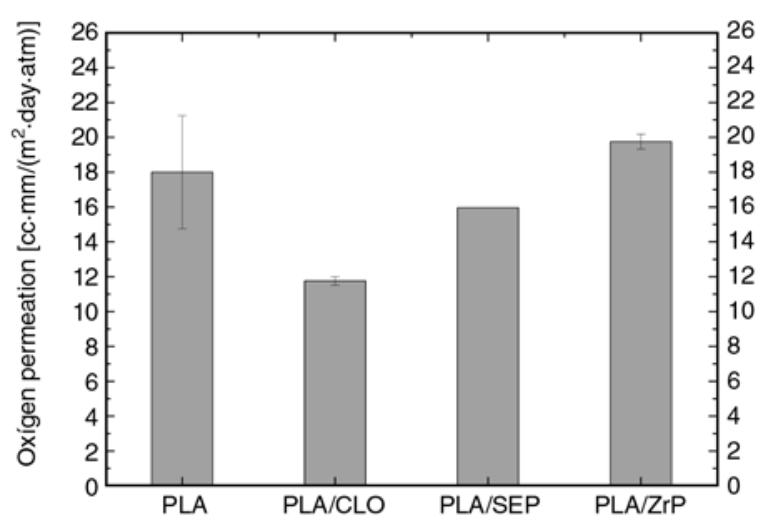

Figure 9. Oxygen gas permeability of PLA and PLA/composites, measured at $23^{\circ} \mathrm{C}$ and $0 \%$ relative humidity 
Table 4. Oxygen permeation of PS, PP, PET films, values taken from Massey [42]

\begin{tabular}{|l|c|}
\hline \multicolumn{1}{|c|}{ Reference } & $\begin{array}{c}\text { Oxygen permeation } \\
{\left[\mathbf{c c} \cdot \mathbf{m m} /\left(\mathbf{m}^{\mathbf{2}} \cdot \mathbf{d a y} \cdot \mathbf{a t m}\right)\right]}\end{array}$ \\
\hline Polystyrene (PS) & $117-157$ \\
\hline Polypropylene (PP) & $59-102$ \\
\hline Polypropylene oriented film (PPof) & $59-63$ \\
\hline Polyethylene terephthalate (PET) film & 3 \\
\hline
\end{tabular}

PLA; however, this decrease is not sufficient to reach the low permeability of PET. The deep understanding of chemical and physical interaction between CLO, SEP and ZrP particles and the polymer could result in the optimization of the melt blending conditions and clay content in order to obtain polymer nanocomposites with the reduced oxygen permeation required for materials with high oxygen barrier properties such as PET, contributing to the development of new bio-based polymer composites for food packaging applications.

\subsection{Optical transparency}

In polymer nanocomposites, it has been reported that film transparency is an effective index for providing information on the size of dispersed particles in the polymer matrix, typically observing aggregate domains larger than visible wavelength could obstruct light, leading to translucent or opaque films [21], while highly dispersed nanoparticles in a transparent polymer matrix result in optically clear nanocomposites in visible light given that the size of particles is smaller than the wavelength [2].

All films of neat PLA and PLA/composites obtained by compression moulding were optically transparent. Indeed, Table 5 shows the cumulative transmission over visible spectra (380-780 nm wavelength) on neat PLA and composites; these results show that the absorption in the visible region, taking into account the experimental error, is not significantly affected by the presence of any particle, therefore the characteristic transparency of PLA film of $50 \mu \mathrm{m}$

Table 5. UV-visible transmission average results of PLA and PLA/nanocomposites from 380-780 nm wavelength. Experimental error 10\%.

\begin{tabular}{|l|c|c|}
\hline \multicolumn{1}{|c|}{ Sample } & $\begin{array}{c}\text { Absorbance } \\
{[\mathbf{A} / \boldsymbol{\mu} \mathbf{m}]}\end{array}$ & $\begin{array}{c}\text { Transmission } \\
{[\mathbf{\%} \mathbf{T} / \mathbf{5 0} \boldsymbol{\mu} \mathbf{m}]}\end{array}$ \\
\hline PLA & 0.0081 & 39 \\
\hline PLA + CLO & 0.0101 & 31 \\
\hline PLA + SEP & 0.0066 & 43 \\
\hline PLA + ZrP & 0.0096 & 33 \\
\hline
\end{tabular}

thick is not considerable reduced in the presence of these particles.

\section{Conclusions}

Poly(lactic acid) (PLA) based nanocomposites prepared by adding $5 \mathrm{wt} \%$ filler content of organically modified montmorillonite (CLO) and unmodified sepiolite (SEP) were obtained by melt blending. WAXS and SEM analysis showed a good dispersion of CLO and SEP into the polymer matrix. PLA containing $\mathrm{ZrP}$ showed a limited dispersion on PLA matrix as compared to CLO, likely due to its significant lower interlayer thickness, leading to formation of a polymer microcomposite.

DSC analysis showed that neat PLA and composites presented no tendency to crystallise on cooling. Nevertheless, it was observed that PLA was able to crystallize on heating, and that the addition of $\mathrm{ZrP}$ can promote the extent of crystallization of the PLA on heating, which can be explained by the regular distribution of $\mathrm{ZrP}$ micronic particles able to act as efficient nucleating agents for PLA crystallization. The dynamo-mechanical results showed improvements in $E^{\prime}$ with the addition of all particles, resulting in a remarkable increase of elastic properties for PLA composites, especially at temperatures close to the glass transition temperature. These $E^{\prime}$ increases were associated to possible interactions between the particles and PLA molecules originated from hydrogen bonding between the carbonyl group of PLA and the hydroxyl groups belong to the structure of CLO, SEP and ZrP. Interestingly, similar increases of $E^{\prime}$ were obtained upon the addition of $\mathrm{ZrP}$ into PLA as compared to CLO and SEP, despite its low dispersion level into the PLA matrix, possibly explained by the high crystallinity of $\mathrm{ZrP}$ particles as well as to the very regular distribution of $\mathrm{ZrP}$ micronic particles along all the polymer matrix.

The melt viscosity and dynamic shear moduli of nanocomposites were also enhanced significantly by the presence of CLO and SEP. The dynamic shear storage modulus, $G^{\prime}$, and loss modulus, $G^{\prime \prime}$ of these nanocomposites, exhibited less frequency dependence than pure PLA at a low frequency range. These results could be attributed to important interactions between PLA and nanocomposites, especially CLO, forming an interconnected structure within the PLA matrix. 
The oxygen permeability of PLA did not significantly vary upon addition of SEP and ZrP particles. Only addition of CLO leaded to an important decrease of the PLA oxygen permeability. Optical transparency measurements showed the transparency of PLA in the visible region not to change significantly with the presence of particles, thus preserving the good optical properties typical of PLA.

The improvements of viscous and/or elastic properties for PLA composites as well as the similar transparency and improved gas barrier properties could provide to these composites an opportunity in the field of packaging. Even more, it is reasonable to expect that by controlling the nanoparticle content and processing conditions, PLA based nanocomposites films with improved properties could be obtained for various purposes of industrial application.

\section{Acknowledgements}

The authors would like to thank gratefully Dr. Simona Ceccia and Emilia Giofreddi for their great support and guidance throughout the measurements and analysis of rheological tests. This work was partially supported by the research project NAMATECH 'Nano-materials and -technologies for intelligent monitoring of safety, quality and traceability in confectionery products' in the frame of Piedmont Region Converging technologies call 2007.

\section{References}

[1] Weber C. L. J.: Biobased packaging materials for the food industry. Report by the EU Directorate 12 (2011).

[2] Sinha Ray S., Okamoto M.: Polymer/layered silicate nanocomposites: A review from preparation to processing. Progress in Polymer Science, 28, 1539-1641 (2003).

DOI: $10.1016 /$ j.progpolymsci.2003.08.002

[3] Coombs J., Hall K.: Non food agro-industrial research information (CD-rom version). CPL Publishing Services, Newbury (2000).

[4] Mangan C.: The green chemical and polymers chain: Fair, agriculture and fisheries including agro-industry, food-technologies, forestry, aquaculture and rural development: $4^{\text {th }}$ framework programme 1994-1998. European Commission, Luxembourg (1998).

[5] Sinha Ray S., Okamoto M.: Biodegradable polylactide and its nanocomposites: Opening a new dimension for plastics and composites. Macromolecular Rapid Communications, 24, 815-840 (2003).

DOI: $\underline{10.1002 / \text { marc. } 200300008}$
[6] Feijoo J. L., Cabedo L., Giménez E., Lagaron J. M., Saura J. J.: Development of amorphous PLA-montmorillonite nanocomposites. Journal of Materials Science, 40, 1785-1788 (2005).

DOI: $10.1007 / \mathrm{s} 10853-005-0694-8$

[7] Singh R. P., Pandey J. K., Rutot D., Degée Ph., Dubois $\mathrm{Ph}$.: Biodegradation of poly( $\varepsilon$-caprolactone $) /$ starch blends and composites in composting and culture environments: The effect of compatibilization on the inherent biodegradability of the host polymer. Carbohydrate Research, 338, 1759-1769 (2003). DOI: $10.1016 / \mathrm{S} 0008-6215(03) 00236-2$

[8] Di Y., Iannace S., Di Maio E., Nicolais L.: Poly(lactic acid)/organoclay nanocomposites: Thermal, rheological properties and foam processing. Journal of Polymer Science Part B: Polymer Physics, 43, 689-698 (2005). DOI: $10.1002 /$ polb.20366

[9] Pollet E., Paul M-A., Dubois P.: New aliphatic polyester layered-silicate nanocomposites. in 'Biodegradable polymers and plastics, Vol 1.' (eds.: Chiellini E., Solaro R.) Kluwer, New York (2003). DOI: $10.1007 / 978-1-4419-9240-622$

[10] Utracki L. A.: Basic elements of polymeric nanocomposites technology. in 'Clay- containing polymeric nanocomposites’ (ed.: Utracki L. A.) Vol 1. Rapra, Shropshire (2004).

[11] Pluta M., Galeski A., Alexandre M., Paul M-A., Dubois P.: Polylactide/montmorillonite nanocomposites and microcomposites prepared by melt blending: Structure and some physical properties. Journal of Applied Polymer Science, 86, 1497-1506 (2002).

DOI: 10.1002/app.11309

[12] Chang J-H., Kim S. J., Joo Y. L., Im S.: Poly(ethylene terephthalate) nanocomposites by in situ interlayer polymerization: The thermo-mechanical properties and morphology of the hybrid fibers. Polymer, 45, 919926 (2004).

DOI: $10.1016 /$ j.polymer.2003.11.037

[13] Utracki L. A., Sepehr M., Boccaleri E.: Synthetic, layered nanoparticles for polymeric nanocomposites (PNCs). Polymers for Advanced Technologies, 18, 1-37 (2007).

DOI: $10.1002 /$ pat.852

[14] Fukushima K., Abbate C., Tabuani D., Gennari M., Camino G.: Biodegradation of poly(lactic acid) and its nanocomposites. Polymer Degradation and Stability, 94, 1646-1655 (2009).

DOI: $10.1016 /$ j.polymdegradstab.2009.07.001

[15] Fukushima K., Tabuani D., Camino G.: Nanocomposites of PLA and PCL based on montmorillonite and sepiolite. Materials Science and Engineering C, 29, 1433-1441 (2009).

DOI: $10.1016 / \mathrm{j} . \mathrm{msec} .2008 .11 .005$ 
[16] Tartaglione G., Tabuani D., Camino G., Moisio M.: PP and PBT composites filled with sepiolite: Morphology and thermal behaviour. Composites Science and Technology, 68, 451-460 (2008).

DOI: 10.1016/j.compscitech.2007.06.023

[17] Brandão L. S., Mendes L. C., Medeiros M. E., Sirelli L., Dias M. L.: Thermal and mechanical properties of poly(ethylene terephthalate)/lamellar zirconium phosphate nanocomposites. Journal of Applied Polymer Science, 102, 3868-3876 (2006).

DOI: 10.1002/app.24096

[18] Sun L., Boo W. J., Browning R. L., Sue H-J., Clearfield A.: Effect of crystallinity on the intercalation of monoamine in $\alpha$-zirconium phosphate layer structure. Chemistry of Materials, 17, 5606-5609 (2005).

DOI: $10.1021 / \mathrm{cm} 051160 \mathrm{i}$

[19] Boo W-J., Sun L., Warren G. L., Moghbelli E., Pham H., Clearfield A., Sue H-J.: Effect of nanoplatelet aspect ratio on mechanical properties of epoxy nanocomposites. Polymer, 48, 1075-1082 (2007).

DOI: $10.1016 /$ j.polymer.2006.12.042

[20] Boo W. J., Sun L. Y., Liu J., Clearfield A., Sue H-J., Mullins M. J., Pham H.: Morphology and mechanical behavior of exfoliated epoxy/ $\alpha$-zirconium phosphate nanocomposites. Composites Science and Technology, 67, 262-269 (2007).

DOI: $10.1016 /$ j.compscitech.2006.08.012

[21] Wu H., Liu C., Chen J., Chang P. R., Chen Y., Anderson D. P.: Structure and properties of $s t a r c h / \alpha$-zirconium phosphate nanocomposite films. Carbohydrate Polymers, 77, 358-364 (2009).

DOI: $10.1016 /$ j.carbpol.2009.01.002

[22] Choudalakis G., Gotsis A. D.: Permeability of polymer/clay nanocomposites: A review. European Polymer Journal, 45, 967-984 (2009).

DOI: $10.1016 /$ j.eurpolymj.2009.01.027

[23] Tartaglione G., Tabuani D., Camino G.: Thermal and morphological characterisation of organically modified sepiolite. Microporous and Mesoporous Materials, 107, 161-168 (2008).

DOI: $10.1016 /$ j.micromeso.2007.04.020

[24] Shariatmadari H., Mermut A. R.: Magnesium- and silicon-induced phosphate desorption in smectite-, palygorskite-, and sepiolite-calcite systems. Soil Science Society of America Journal, 63, 1167-1173 (1999). DOI: $10.2136 /$ sssaj1999.6351167x

[25] Herrero C. R., Morales E., Acosta J. L.: The influence of sepiolite on the dynamic moduli and thermal transition of compatible and incompatible blends based on poly(vinylidene fluoride). Die Angewandte Makromolekulare Chemie, 205, 97-106 (1993).

DOI: 10.1002/apmc.1993.052050108
[26] Herrero C. R., Morales E., Acosta J. L.: Compatibilization of semicrystalline polymeric alloys through sepiolite addition. Journal of Applied Polymer Science, 51, 1189-1197 (1994).

DOI: 10.1002/app.1994.070510705

[27] Acosta J. L., González L., Ojeda M. C., Del Río C.: Ionomer composites based on sepiolite/hydrogenated poly(styrene butadiene) block copolymer systems. Journal of Applied Polymer Science, 86, 3512-3519 (2002).

DOI: $10.1002 / a p p .11113$

[28] González L., Rodríguez A., Marcos-Fernández A., Del Campo A.: Reinforcing effect and electrical properties of ethylene-propylene rubber filled with calcined sepiolite. Journal of Applied Polymer Science, 79, 714718 (2001).

DOI: $10.1002 / 1097-4628(20010124) 79: 4<714::$ AIDAPP160>3.0.CO;2-J

[29] Bokobza L., Chauvin J-P.: Reinforcement of natural rubber: Use of in situ generated silicas and nanofibres of sepiolite. Polymer, 46, 4144-4151 (2005).

DOI: $10.1016 /$ j.polymer.2005.02.048

[30] Jones B. F., Galán E. S.: Sepiolite and palygorskite. Mineralogical Society of America, 19, 631-674 (1988).

[31] Ahlrichs J. L., Serna C., Serratosa J. M.: Structural hydroxyls in sepiolites. Clays and Clay Minerals, 23, 119-124 (1975).

DOI: $10.1346 / C C M N .1975 .0230207$

[32] Serratosa J. M.: Surface properties of fibrous clay minerals (paligorskite and sepiolite). in 'Proceedings of international clay conference 1978' (Mortland M. M., Farme V. C.) Amsterdam, Elsevier, 99-110 (1979).

[33] Clearfield A., Smith G. D.: Crystallography and structure of $\alpha$-zirconium bis(monohydrogen orthophosphate) monohydrate. Inorganic Chemistry, 8, 431-436 (1969).

DOI: $10.1021 /$ ic50073a005

[34] Liu X-Q., Wang D-Y., Wang X-L., Chen L., Wang Y$Z$.: Synthesis of organo-modified $\alpha$-zirconium phosphate and its effect on the flame retardancy of IFR poly(lactic acid) systems. Polymer Degradation and Stability, 96, 771-777 (2001).

DOI: $10.1016 /$ j.polymdegradstab.2011.02.022

[35] Alberti G., Costantino U., Casciola M., Vivani R.: Proton conductivity of zirconium carboxy n-alkyl phosphonates with an $\alpha$-layered structure. Solid State Ionics, 46, 61-68 (1991). DOI: 10.1016/0167-2738(91)90129-Y

[36] Costantino U., Vivani R., Zima V., Cernoskova E.: Thermoanalytical study, phase transitions, and dimensional changes of $\alpha-\mathrm{Zr}\left(\mathrm{HPO}_{4}\right)_{2} \cdot \mathrm{H}_{2} \mathrm{O}$ large crystals. Journal of Solid State Chemistry, 132, 17-23 (1997). DOI: $10.1006 /$ jssc. 1997.7385 
[37] Fukushima K., Tabuani D., Abbate C., Arena M., Rizzarelli P.: Preparation, characterization and biodegradation of biopolymer nanocomposites based on fumed silica. European Polymer Journal, 47, 139-152 (2011). DOI: $10.1016 /$ j.eurpolymj.2010.10.027

[38] Di Y., Iannace S., Di Maio E., Nicolais L.: Nanocomposites by melt intercalation based on polycaprolactone and organoclay. Journal of Polymer Science Part B: Polymer Physics, 41, 670-678 (2003). DOI: $10.1002 /$ polb.10420

[39] Ruiz-Hitzky E., Darder M., Aranda P., del Burgo M. A. M., del Real G.: Bionanocomposites as new carriers for influenza vaccines. Advanced Materials, 21, 41674171 (2009).

DOI: $10.1002 / \mathrm{adma} .200900181$
[40] Ruiz-Hitzky E.: Molecular access to intracrystalline tunnelsof sepiolite. Journal of Materials Chemistry, 11, 86-91 (2001).

DOI: $10.1039 / \mathrm{b} 003197 \mathrm{f}$

[41] Sinha Ray S., Yamada K., Okamoto M., Ueda K.: New polylactide-layered silicate nanocomposites. 2. Concurrent improvements of material properties, biodegradability and melt rheology. Polymer, 44, 857-866 (2003). DOI: $10.1016 / \mathrm{S} 0032-3861(02) 00818-2$

[42] Massey K. L.: Permeability properties of plastics and elastomers. A guide to packaging and barrier materials. Plastics Design Library, New York (2003). 